\title{
Safety concerns with the Centers for Disease Control opioid calculator
}

\author{
Jeffrey Fudin ${ }^{1-4}$ \\ Mena Raouf ${ }^{2}$ \\ Erica L Wegrzyn ${ }^{2-4}$ \\ Michael E Schatman ${ }^{5,6}$ \\ 'Scientific and Clinical Affairs, \\ Remitigate, LLC, Delmar, NY, USA; \\ ${ }^{2}$ Stratton VA Medical Center, Albany, \\ NY, USA; ' Western New England \\ University College of Pharmacy, \\ Springfield, MA, USA; ${ }^{4}$ Albany College \\ of Pharmacy \& Health Sciences, \\ Albany, NY, USA; ${ }^{5}$ Research and \\ Network Development, Boston \\ Pain Care, Waltham, MA, USA; \\ ${ }^{6}$ Department of Public Health \& \\ Community Medicine, Tufts University \\ School of Medicine, Boston, MA, USA
}

Correspondence: Jeffrey Fudin Remitigate, LLC

357 Delaware Ave \#214,

Delmar, NY 12054, USA

Email Jeffrey.fudin@remitigate.com
This article was published in the following Dove Press journal: Journal of Pain Research

\section{Introduction}

Morphine milligram equivalence (MME) and other comparable acronyms have been employed in federal pain guidelines and used by policy makers to limit opioid prescribing. ${ }^{1-5}$ On March 18, 2016, the Centers for Disease Control (CDC) released its Guideline for Prescribing Opioids for Chronic Pain. ${ }^{1}$ The guidelines provided 12 recommendations for "primary care clinicians prescribing opioids for chronic pain outside of active cancer treatment, palliative care, and end-of-life care". One of the $\mathrm{CDC}$ recommendations states that clinicians "should avoid increasing dosage to $\geq 90$ $\mathrm{MME} /$ day or carefully justify a decision to titrate dosage to $\geq 90 \mathrm{MME} / \mathrm{day}$ ". ${ }^{1}$

There has been controversy regarding the methodology used to develop the CDC opioid prescribing guidelines, ${ }^{6,7}$ including concern regarding the bias of the guideline committees due to its domination by the anti-opioid group, Physicians for Responsible Opioid Prescribing. ${ }^{8}$ The CDC used the Grading of Recommendations, Assessment, Development, and Evaluation (GRADE) framework for producing evidence-based recommendations; however, the guidelines deviated significantly from the established GRADE methodology without associated justification. ${ }^{9}$ There is a significant mismatch in the strength of the recommendations made in the guidelines and the supporting evidence. When considering that all recommendations were based on level 3 or 4 evidence yet eleven of the recommendations were assigned grade $\mathrm{A}$, this is a major deviation from the National Clearing House guidelines on levels of evidence and grades of recommendations. ${ }^{10}$ The $\mathrm{CDC}$ guidelines excluded studies with observation periods of less than 1 year for basing their recommendations on the benefits and risks of opioids. According to the CDC guidelines, "No evidence shows a long-term benefit of opioids in pain and function versus no opioids for chronic pain with outcomes examined at least 1 year later". ${ }^{1}$ This is inconsistent with current standards on analgesic study durations in chronic pain. The international harmonized standards adopted by the United States for approval of chronic pain interventions recommend 12 weeks for efficacy assessment. ${ }^{11}$ Tayeb et al conducted a review evaluating analgesic trial durations for opioids, antidepressants, anticonvulsants, nonsteroidal anti-inflammatory drugs, and behavioral therapy. ${ }^{12}$ The authors found that nearly all trials had active treatment durations of 12 weeks or less across 869 articles. Commenting on CDC's recommendation on nonopioid therapies, Tayeb et al wrote, "if a one year minimum threshold for duration of active treatment were required to justify using any of the 
major typical therapies for chronic pain, then none of these nonopioid therapies could be recommended." 12

\section{CDC MME calculator}

Along with the strategies employed by MME prescribing thresholds, the CDC provided a checklist for opioid prescribing, along with additional tools to guide clinicians on implementing the recommendations. These tools include the CDC's "Opioid Guide App" for smartphone with the slogan "Managing Chronic Pain Is Complex, But Accessing Prescribing Guidance Has Never Been Easier". ${ }^{13}$ The App includes an MME calculator requiring the user to enter different opioid(s) along with the daily dose to calculate the total MME daily dose. The App provides recommendations based on the calculated MME. For 50-89 MME/day, a message appears stating "For $\geq 50 \mathrm{MME} /$ day, use extra precautions and reassess pain and function more frequently. Discuss reducing dose or tapering/discontinuing opioids if benefits do not outweigh harms". For $\geq 90$ MME, a message appears stating, "Caution: $\geq 90$ MME may increase risk for overdose. Avoid or carefully justify doses $>90 \mathrm{MME} /$ day; consider referring to specialist and schedule reassessment at least every 3 months" ${ }^{13}$ While we agree with the intended concept to improve safety, there are conspicuous flaws in the posted calculator that could significantly affect safety and incur increased risk of mortality and morbidity.

\section{The case with methadone}

A major flaw with the CDC calculator is the methadone to morphine conversion, as the conversion is neither linear nor bidirectional due to the unique and complex pharmacokinetics of methadone. Methadone's unique additional mechanism of $N$-methyl-D-aspartate antagonism is thought to attenuate developed tolerance as the dose of other opioids is increased. ${ }^{14}$ Fudin et al pointed out significant swings at dose interval breaks and developed a mathematical model, The Fudin Factor ${ }^{\circ}$, that eliminates peaks and troughs with methadone dose conversions. ${ }^{14}$ The CDC calculator does not account for these significant swings and can be dangerous when used by clinicians inexperienced with methadone dosing. Table 1 demonstrates an example of the abrupt upsurge at dose interval breaks calculated by the CDC Opioid Guideline Mobile App.

Methadone conversion is very complex, and if built into a calculator, extensive warnings are in order. Accordingly, a balance between two different equations should be embedded in the software background, such that the conversion remains conservative in either direction when converting
Table I Methadone MME as calculated by the CDC Opioid Guideline Mobile App ${ }^{13}$

\begin{tabular}{ll}
\hline Guideline resources: CDC Opioid & Guideline Mobile App \\
\hline $\begin{array}{ll}\text { Methadone daily } \\
\text { dose }(\mathbf{m g})\end{array}$ & $\begin{array}{l}\text { Morphine milligram } \\
\text { equivalent }(\mathbf{m g})\end{array}$ \\
\hline 20 & 80 \\
21 & 168 \\
40 & 320 \\
41 & 410 \\
\hline
\end{tabular}

Abbreviations: MME, morphine milligram equivalence; CDC, Centers for Disease Control.

to or from methadone. ${ }^{14}$ Considering that methadone contributed to nearly one in three prescription opioid overdose deaths despite accounting for less than $2 \%$ of the prescription opioid sales examining opioid prescriptions and deaths from 1999-2010, it begs the question of whether or not many, if not most of these deaths, could be attributable to inaccurate dosing during opioid rotation when switching to or from methadone. $^{15}$

\section{The case with tapentadol}

Another flaw of the CDC calculator is the proposed MME for tapentadol. According to the CDC calculator, tapentadol $100 \mathrm{mg}$ has an MME of $40 .{ }^{13}$ Tapentadol is a centrally acting analgesic with dual mechanisms, mu-receptor agonism and norepinephrine reuptake inhibition. ${ }^{16}$ Because of its dual mechanisms, the equianalgesic dosing found in clinical trials should not be used to predict nonanalgesic effects such as respiratory depression.

Tapentadol's package insert does not list an MME or equianalgesic dose conversion because no study to date has been powered to appropriately assess conversion. ${ }^{17}$ In clinical trials, tapentadol extended-release (ER) (100-250 mg bid) had comparable analgesic effect to oxycodone controlled release (CR) $(25-50 \mathrm{mg}$ bid) in moderate to severe osteoarthritis pain, low back pain, and pain related to diabetic peripheral neuropathy. ${ }^{18}$ The key phrase here is "analgesic effect", which by definition, cannot be used to attribute nonanalgesic effects such as respiratory depression.

Tapentadol is 18 times less potent than morphine for mu-opioid receptor activation, but only 2-3 times less potent in providing analgesia. ${ }^{17}$ The disparity between tapentadol's affinity and analgesic potency is presumably due to its activity on norepinephrine reuptake inhibition, which is involved in descending pain modulation. Tapentadol's activity on norepinephrine targets neuropathic pain, and it accordingly carries US Food and Drug Administration approval for treatment of pain related to diabetic peripheral neuropathy. ${ }^{17}$ Therefore, 
patients with neuropathic pain are likely to require a lower "MME" when prescribed tapentadol relative to other traditional opioids.

Based on mu-receptor potency, tapentadol's MME for nonanalgesic effects related to opioid receptor activation, such as respiratory depression, would be less than equianalgesic doses determined through clinical trials; therefore, applying this equianalgesic dose conversion when switching from tapentadol to a traditional opioid agonist (eg, morphine, hydrocodone, oxycodone) will yield higher opioid receptor activation and increased respiratory depression. For this reason, the CDC calculator MME for tapentadol represents a major safety issue if used when converting to or from tapentadol. Based on the CDC's calculator's, a patient on a tapentadol daily dose of 200 mg will have a calculated MME of $80 \mathrm{mg} \cdot{ }^{13}$ Therefore, if this patient is converted to a daily dose of $80 \mathrm{mg}$ of morphine, she/he will have higher opioid effects relative to their previous dose of tapentadol, and subsequently, would be placed at increased risk for opioid overdose.

We do commend CDC for not including buprenorphine in their online Opioid Guide App. Buprenorphine is a partial agonist at the mu-receptor and has antagonist activity at the kappa receptor. ${ }^{19}$ This results in a plateau effect of carbon dioxide accumulation as the dose increases and it is associated with a decreased incidence of opioid-induced respiratory depression. Additionally, buprenorphine has a significantly higher affinity for the mu-receptor compared to traditional pure mu agonists such that it will prevent their binding. This can represent a potentially dangerous situation when converting from buprenorphine to a pure mu agonist such as oxycodone. If a patient was not appropriately tapered off buprenorphine prior to oxycodone initiation, it could be expected to provide minimal analgesic effects, as buprenorphine inhibits oxycodone binding with the receptor. This could result in an unanticipated overdose if not appropriately considered when dosing oxycodone.

\section{Ethical considerations}

Recently, a considerable amount of attention has been paid to the CDC's role in dealing with the public health crisis of chronic pain. To say the least, the organization's conduct has eroded both public and clinician confidence, as well as violating accepted policy. First, CDC's process of developing an opioid guideline has been criticized as unscientific and lacking transparency, as well as for being written by a group "stacked" with members of a zealous anti-opioid group. ${ }^{20-22}$ The creation of this guideline was clearly inconsistent with the Institute of Medicine's recommended standards for the creation of clinical practice guidelines. ${ }^{23}$ More recently, Schatman and Ziegler noted that such manipulation of data is contributing to the tragic climate of opiophobia and oligoanalgesia, thereby resulting in needless suffering among patients with chronic pain. ${ }^{24}$ These transgressions are compounded by the CDC's promotion of a flawed App for opioid conversion, which may have the potential to cause more overdoses than careful manual conversion when transitioning therapy between opioids!

\section{Conclusion}

MME dosing was designed in an attempt to examine opioids with similar analgesic effects and should not be used to determine an exact mathematical dosing conversion. The pharmacology and unique properties of each opioid and patient individuality must be considered when a therapeutic opioid conversion is contemplated. Conversion should not simply rely on a mathematical formula embedded within the CDC calculator software. Furthermore, the current calculation for methadone employed by the calculator could allow for potentially dangerous conversions. This is especially problematic considering this calculator is intended to target nonspecialist, general practitioners. We expect a higher level of scientific accuracy and integrity from an agency entrusted to protect citizens' health and welfare.

\section{Disclosure}

This article is the sole work of the authors, and stated opinions or assertions do not reflect the opinions of employers, employee affiliates, or any pharmaceutical companies listed. It was not prepared as part of the authors' duties as federal employees. Jeffrey Fudin reports: Astra Zeneca (Speakers Bureau); Daiichi Sankyo (Advisory Board); Egalet (consultant, Advisory Board); Quest Labs (Advisory Board; Remitigate, LLC [Owner]). Michael Schatman reports: Depomed (consultant). The authors report no other conflicts of interest in this work.

\section{References}

1. Dowell D, Haegerich TM, Chou R. CDC Guideline for prescribing opioids for chronic pain - United States, 2016. MMWR Recomm Rep. 2016;65(1):1-49.

2. Washington State Department of Health. Opioid Prescribing. DOH Available from: http://www.doh.wa.gov/ForPublicHealthandHealthcareProviders/HealthcareProfessionsandFacilities/PainManagement/ FrequentlyAskedQuestionsforPractitioners/MorphineEquivalentDosageMed. Accessed April 23, 2017.

3. Health Care Association of New Jersey. Pain Management Guideline. Hamilton: HCANJ; 2006. Available from: http://www.hcanj.org/ files/2013/09/hcanjbp_painmgmt2_3.pdf. Accessed October 4, 2017. 
4. Washington State Department of Labor and Industries. Guideline for Prescribing Opioids to Treat Pain in Injured Workers. Olympia: L\&I; 2013. Available from: http://lni.wa.gov/ClaimsIns/Files/OMD/ MedTreat/FINALOpioidGuideline010713.pdf. Accessed October 4, 2017.

5. University of Michigan Health System. Managing Chronic Nonterminal Pain in Adults Including Prescribing Controlled Substances. Ann Arbor: UHMS; 2011.

6. American Cancer Society Cancer Action Network. American Cancer Society Cancer Action Network Comments on CDC Draft Opioid Prescribing Guidelines. American Cancer Society Cancer Action Network; 2015. Available from: https://www.acscan.org/sites/default/files/ ACSCAN_Comments_CDC_Opioid_Guidelines_Final.pdf. Accessed April 25, 2017.

7. Argoff CE. New CDC Opioid Guideline: The Good, the Bad, the Ugly. Medscape; 2016. Available from: http://www.medscape.com/ viewarticle/863183\#vp_4. Accessed April 25, 2017.

8. painnewsnetwork.org. Anson P. Bias and conflict of interest in opioid guidelines study. Pain News Network; 2017. Available from: https:// www.painnewsnetwork.org/stories/2017/1/17/bias-and-conflict-ofinterest-in-new-opioid-research. Accessed April 25, 2017.

9. Guyatt GH, Oxman AD, Vist GE, et al. GRADE: an emerging consensus on rating quality of evidence and strength of recommendations. $B M J$. 2008;336(7650):924-926.

10. Shekelle PG, Woolf SH, Eccles M, Grimshaw J. Developing clinical guidelines. West J Med. 1999;170(6):348-351.

11. International Council for Harmonisation of Technical Requirements for Pharmaceuticals for Human Use. The extent of population exposure to assess clinical safety for drugs intended for longterm treatment of non-life-threatening conditions E1. International Council for Harmonisation of Technical Requirements for Pharmaceuticals for Human Use; 1994. Available from: http://www.ich.org/fileadmin/Public_Web_Site/ ICH_Products/Guidelines/Efficacy/E1/Step4/E1_Guideline.pdf. Accessed April 23, 2017.

12. Tayeb BO, Barreiro AE, Bradshaw YS, Chui KK, Carr DB. Durations of opioid, nonopioid drug, and behavioral clinical trials for chronic pain: adequate or inadequate? Pain Med. 2016;17(11):2036-2046.
13. Centers for Disease Control and Prevention. Guideline Resources: CDC Opioid Guideline Mobile App. CDC. Available from: https://www. cdc.gov/drugoverdose/prescribing/app.html. Accessed April 23, 2017.

14. Fudin J, Marcoux MD, Fudin JA. Mathematical model for methadone conversion examined. Practical Pain Manag. 2012;12(8):46-51.

15. National Vital Statistics System, 1999-2009; Drug Enforcement Administration Automation of Reports and Consolidated Order Systems (ARCOS), 1999-2010. Available from: https://www.cdc.gov/drugoverdose/data/overdose.html. Accessed October 4, 2017.

16. Tzchentke TM, Christoph T, Kögel B et al. (-)-(1R,2R)-3-(3-dimethylamino-1-ethyl-2-methyl-propyl)-phenol hydrochloride (tapentadol $\mathrm{HCl}$ ): a novel mu-opioid receptor agonist/norepinephrine reuptake inhibitor with broad-spectrum analgesic properties. J Pharmacol Exp Ther. 2007;323(1):265-276.

17. Nucynta (tapentadol) [package insert]. Titusville NJ: Janssen Pharmaceuticals, Inc.; 2009.

18. Afilalo M, Morlion B. Efficacy of tapentadol ER for managing moderate to severe chronic pain. Pain Physician. 2013;16(1):27-40.

19. Khanna IK, Pillarisetti S. Buprenorphine - an attractive opioid with underutilized potential in treatment of chronic pain. J Pain Res. 2015;8:859-870.

20. Washington Legal Foundation. Re: Guideline for Prescribing Opioids for Chronic Pain. Washington Legal Foundation; 2015. Available from: http://www.wlf.org/upload/litigation/misc/CDCComments-Opioids. pdf. Accessed October 21, 2017.

21. The American Academy of Pain Medicine. Re: Docket No. CDC2015-0112; Proposed 2016 Guideline for Prescribing Opioids for Chronic Pain. The American Academy of Pain Medicine; 2016. Available from: http://www.painmed.org/files/aapm-letter-to-cdc-proposed2016-guidelines-for-prescibing.pdf. Accessed on October 21, 2017.

22. Pain News Network [homepage on the Internet]. Anson P. PROP helped craft CDC opioid guidelines. Pain Network News; 2015. Available from: https://www.painnewsnetwork.org/stories/2015/9/21/prop-helped-draftcdc-opioid-guidelines. Accessed October 21, 2017.

23. Institute of Medicine. Clinical Practice Guidelines We Can Trust. Washington, DC: National Academies Press; 2011.

24. Schatman ME, Ziegler SJ. Pain management, prescription opioid mortality, and the CDC: is the devil in the data? J Pain Res. 2017;10:2489-2495.

Dove Medical Press encourages responsible, free and frank academic debate. The content of the Journal of Pain Research 'Editorial' section does not necessarily represent the views of Dove Medical Press, its officers, agents, employees, related entities or the Journal of Pain Research editors. While all reasonable steps have been taken to confirm the content of each Editorial, Dove Medical Press accepts no liability in respect of the content of any Editorial, nor is it responsible for the content and accuracy of any Editorial.

\section{Publish your work in this journal}

The Journal of Pain Research is an international, peer reviewed, open access, online journal that welcomes laboratory and clinical findings in the fields of pain research and the prevention and management of pain. Original research, reviews, symposium reports, hypothesis formation and commentaries are all considered for publication.

\section{Dovepress}

The manuscript management system is completely online and includes a very quick and fair peer-review system, which is all easy to use. Visit http://www.dovepress.com/testimonials.php to read real quotes from published authors. 